\title{
Oriented Periodic Mesoporous Organosilica (PMO) Film with Organic Functionality Inside the Channel Walls**
}

\author{
By Ömer Dag, Chiaki Yoshina-Ishii, Tewodros Asefa, Mark J. MacLachlan, Hiltrud Grondey, \\ Neil Coombs, and Geoffrey A. Ozin*
}

The first examples of an oriented periodic mesoporous organosilica (PMO) film, containing a variety of organic groups (ethane, ethene, benzene, thiophene) inside the channel walls, are reported. The mesostructure of the PMO film appears oriented with respect to the surface of the underlying glass substrate. Liquid-crystal topological defects in the precursor gels are replicated in the resulting PMO film and are evident in polarized optical microscopy images, recorded between crossed-polarizers, which show fan-type optical birefringence texture characteristic of the mesostructure.

\section{Introduction}

Materials containing periodic arrays of mesoscopic voids are attractive for many applications, such as molecular sieving, ${ }^{[1]}$ chromatographic media, ${ }^{[2]}$ and size and shape selective catalysts. ${ }^{[3]}$ They may also serve as hosts for monodisperse ceramic, semiconductor, ${ }^{[4]}$ metallic, ${ }^{[5]}$ and magnetic nanomaterials. ${ }^{[6]}$ In 1992, the report of liquid-crystal templating by Kresge and coworkers $^{[7]}$ initiated a surge of research into mesoporous silica and "chemistry in the channels". As a consequence of their uniform pore sizes, which can be tuned between 2-10 nm, these materials have been used to host a variety of organic, inorganic, organometallic, and polymeric guests. ${ }^{[8]}$ Stucky has designed a laser using mesoporous silica as a host. ${ }^{[9]}$

The liquid-crystal templating approach has been extended to develop mesoporous materials constructed from various inorganic species (e.g., $\mathrm{TiO}_{2}, \mathrm{ZrO}_{2}, \mathrm{Pt}, \mathrm{CdS}, \mathrm{M} / \mathrm{Ge}_{4} \mathrm{~S}_{10}$ ). ${ }^{\left[{ }^{[0-14]} \text { While }\right.}$ these materials have useful properties of their own, they lack the tunability and control that is familiar to organic chemistry. Ideally, one could incorporate moieties from the organic chemist's toolbox into the mesoporous frameworks.

We and others have recently and independently described the surfactant-templated assembly of periodic mesoporous organosilicas (PMOs). ${ }^{[15-20]}$ In our approach, liquid-crystal templated hydrolytic polycondensation of bis(triethoxysilyl)ethylene, $(\mathrm{EtO})_{3} \mathrm{SiCH}=\mathrm{CHSi}(\mathrm{OEt})_{3}$, formed a novel hybrid

[*] Prof. G. A. Ozin, C. Yoshina-Ishii, T. Asefa, Dr. M. J. MacLachlan, Dr. H. Grondey, Dr. N. Coombs

Materials Chemistry Research Group

Department of Chemistry

University of Toronto

80 St. George Street, Toronto, ON M5S 3H6 (Canada)

E-mail: gozin@alchemy.chem.utoronto.ca

Prof. Ö. Dag

Department of Chemistry

Bilkent University

Ankara 06533 (Turkey)

[**] We gratefully acknowledge financial support of this research from the Natural Sciences and Engineering Research Council of Canada (NSERC) MJM thanks NSERC for post-graduate (1995-1999) and post-doctoral (1999-2001) fellowships. GAO thanks the Killam Foundation for an Isaac Walton Killam Foundation Fellowship (1995-1997). periodic mesoporous silica in which the functional organic group resides "inside" the walls of the material. ${ }^{[15]}$ The xerogel counterparts are amorphous organosilicates with a broad chaotic distribution of pore sizes and as a consequence lack the size and shape selectivity desired for applications such as catalysis, separations, and host-guest inclusion. While xerogels have incorporated organic groups since their conception, ${ }^{[21]}$ until recently there were few reports of periodic mesoporous silica composite materials containing a "terminally" bonded ${ }^{[22,23]}$ and none for a "bridge-bonded" organic moiety as an integral part of the framework, which enables "chemistry of the channels".

The incorporation of organic groups directly into the framework has several distinct advantages over terminally bonded organic groups. First, up to $100 \%$ of the Si atoms in the PMOs can be connected to organic groups. For comparison, mesoporous silica with terminally bonded organic groups becomes disordered above ca. $25 \%$ organosilicon content. Second, the organic groups are homogeneously distributed in the framework and contain organic groups inside the walls of the mesoporous material. Third, the organic group is a structural component of the framework and, thus, imparts unique physical characteristics on the framework. By varying the organic group, the framework density, electrical properties, and optical properties would be expected to vary. By analogy to polymer chemistry, the organic groups incorporated into the walls of the mesoporous material affect the "backbone", whereas terminally bonded organic groups in MCM-41 are like "side-chain" groups.

The morphology of materials, such as in the case of periodic mesoporous silica, often controls their function and utility. In this regard, the periodic mesoporous organosilicas will be no exception. In this paper we report the synthesis of oriented PMO film in which ethane, ethene, thiophene, and benzene groups are housed "inside" the walls. We also employed nonionic, lyotropic liquid-crystal templating as the preferred route to these first examples of film morphologies of the periodic mesoporous organosilicas. This is an important step in the utilization of these materials, for example as size and shape selective catalysts, molecule discriminating membranes, controlled chemical delivery vehicles, and chemically tunable composites. 


\section{Results and Discussion}

In this study, we prepared PMO films using multiple bis(triethoxysilyl)organic precursors, $(\mathrm{EtO})_{3} \mathrm{Si}-\mathrm{R}-\mathrm{Si}(\mathrm{OEt})_{3}$, containing the bridging organic groups $\mathrm{R}=$ ethane, ethene, 2,5-thiophene, and 1,4-benzene (denoted BTA, BTE, BTT, and BTP, respectively (Scheme 1)). The success of the synthesis (see Experimental) hinged on forming a homogeneous clear solu-

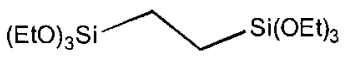

BTA<smiles>CCO[SiH2]c1ccc([SiH2]C(C)C)s1</smiles>

BTT

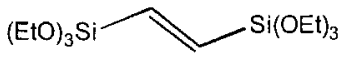

BTE

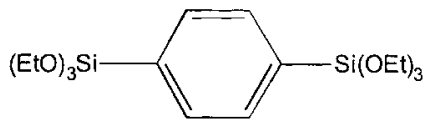

BTP
Scheme 1.

tion of the surfactant, water, acid, and organosilica source. This could be achieved either by adding methanol or heating the mixture before removing the hydrolysis products. Extra precaution must be taken to apply gentle vacuum for the evacuation of the hydrolysis product, ethanol. Excessive evacuation may lead to loss of water, an ingredient required for the formation of the liquid crystalline phase. Upon spreading the mixture on a glass slide, it became viscous in 10-20 min. In this time frame, optical birefringence with a fan texture was observed in the sample with a polarizing optical microscope (POM) and was replicated in the final products. The materials produced in this way were characterized using POM, powder X-ray diffraction (PXRD), solid-state nuclear magnetic resonance (NMR) spectroscopy $\left({ }^{1} \mathrm{H},{ }^{13} \mathrm{C},{ }^{29} \mathrm{Si}\right)$, transmission electron microscopy (TEM), and micro-Raman spectroscopy.

The formation of the PMO film was monitored by POM, Figure 1. The fan texture of the reaction mixture first appeared upon removal of the alcoholic hydrolysis byproduct and remained during the organosilicate hydrolytic polycondensation. The sharpness of the texture is a strong indicator of a high degree of orientation of the mesostructure in the film. Note that if the polymerization of the organosilicate was faster than

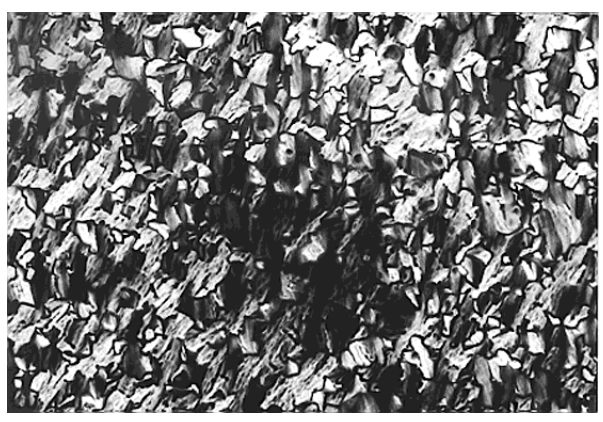

Fig. 1. Photograph of fan-type optical birefringence texture of an as-synthesized oriented PMO film observed with the polarizing optical microscope between crossed polarizers. the formation of the liquid crystal phase, or if the polymerization was very slow and water evaporated, then the mesostructure may not form or it may collapse. To maximize the chances of a liquid-crystal templating mechanism ${ }^{[24,25]}$ and to ensure the formation of a PMO, it was important to control the reactivity of the precursors with the solvent and acid concentrations and the temperature of the reaction mixture.

The PXRD patterns for the as-synthesized PMO films containing, for example ethene and 2,5-thiophene as the bridgebonded group inside the channel wall, are shown in the top and bottom traces respectively of Figure 2a. Four low-angle diffraction peaks were resolved, which could be indexed as (100), (002), (101), and (112) reflections of an oriented 3D hexagonal symmetry mesostructure. ${ }^{[2]}$ Unfortunately, as-synthesized PMO film samples were not robust enough to be ground without degrading the integrity of the mesostructure.
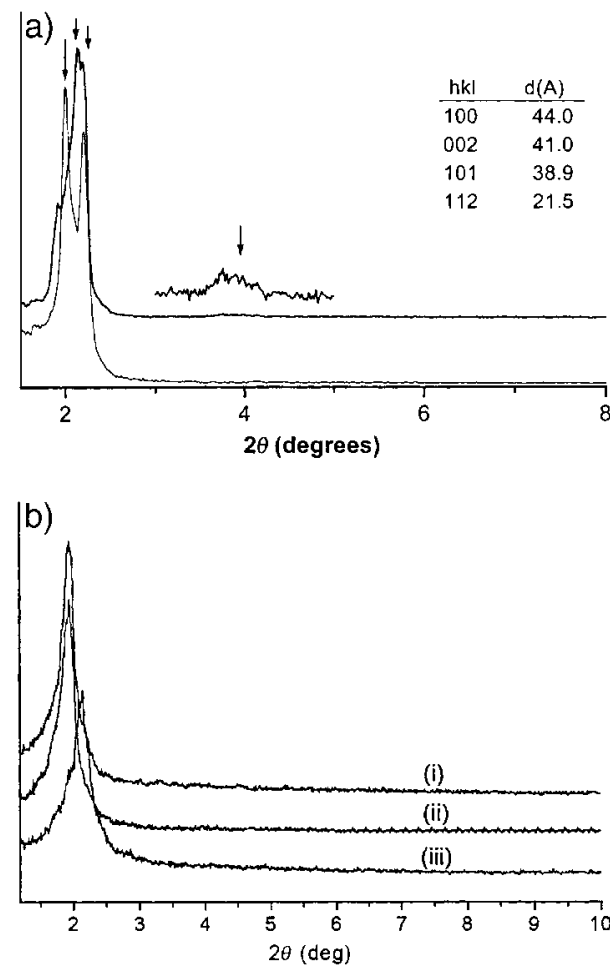

Fig. 2. a) Representative PXRD pattern of an as-synthesized PMO film sample (top BTE, bottom BTT) and b) PXRD patterns of BTT oriented mesoporous organosilica ground film sample i) as-synthesized and washed, ii) heated under acid/water vapor for $20 \mathrm{~h}$, and iii) heated under acid/water vapor for $45 \mathrm{~h}$.

In an effort to increase the mechanical robustness of the PMO film samples, further polymerization of the organosilica framework was encouraged by heating the as-synthesized film at $80^{\circ} \mathrm{C}$ for $20 \mathrm{~h}$ and $45 \mathrm{~h}$ under an acid/water vapor atmosphere. An example of a PXRD pattern of a BTT ground-up film sample treated in this manner is shown in Figure $2 b$. Clearly post-treatment does induce further condensation polymerization of silanols in the organosilica mesostructure. This is seen by a shift of the (100) reflection to higher angles corresponding to shrinkage of the unit cell. However the structure still remains insufficiently mechanically robust to prevent loss of some mesostructural order caused by grinding the film to a powder, which is seen by broadening of the (100) reflection 
and concomitant loss of its intensity and that of higher angle peaks. Significantly, the resolution of the optical birefringence POM images of these post-treated PMO film samples improves, indicating that the additional degree of polymerization, while not much improving the mechanical stability, does enhance the overall mesostructural order of the PMO film.

TEM images of post-treated PMO materials are consistent with the PXRD results, showing preferred orientation of the mesostructure with respect to the surface of the film. As mentioned above, the as-synthesized film samples have a low degree of polymerization, and are mechanically soft. They are not well suited for embedding, microtoming, and sectioning, which is required for TEM imaging of the PMO film. By contrast, heated and acid-polymerized samples show clear mesostructural order in their TEM images (Fig. 3), consistent with the correspondingly improved optical birefringence images seen by polarized optical microscopy.

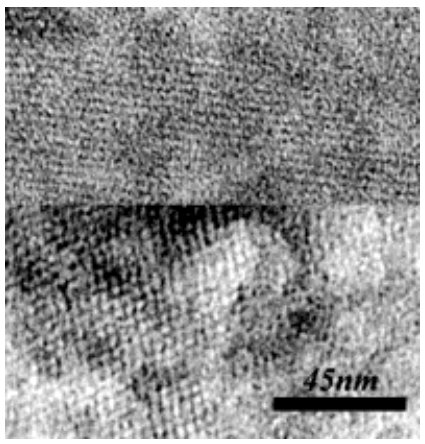

Fig. 3. Representative TEM image of a microtomed section of an as-synthesized oriented PMO film sample.

Micro-Raman spectroscopy spectra display fingerprint vibrations corresponding to $v \mathrm{Si}-\mathrm{C}, v \mathrm{C}=\mathrm{C}$, and $\delta \mathrm{CH}_{2}$ stretching and bending modes of the bridging organic group inside the framework at around $500-600,1400-1600$, and $1410 \mathrm{~cm}^{-1}$, respectively, as well as surfactant related peaks, see Figure 4a. The surfactant modes are relatively broad and diminish upon washing the film samples (Fig. 4b). The BTP-based film displays intense fingerprint vibrational modes at 1598, 1106, 781, and $637 \mathrm{~cm}^{-1}$ due to the bridging benzene moiety. The broad peak at $590 \mathrm{~cm}^{-1}$ is most likely due to a $\nu \mathrm{Si}-\mathrm{C}$ stretching mode of the benzene within the framework. The BTT material displays peaks at around $595 \mathrm{~cm}^{-1}$ and $756 \mathrm{~cm}^{-1}$ due to $\nu \mathrm{Si}-\mathrm{C}$ and $\nu \mathrm{C}-\mathrm{S}$ stretching modes. The strongest peak in the 2,5-thiophenebriged sample is observed at $1419 \mathrm{~cm}^{-1}$, which is assigned to the ring $v \mathrm{C}=\mathrm{C}$ mode.

The BTA and BTE materials display peaks at $1416 \mathrm{~cm}^{-1}$ $\left(\delta \mathrm{CH}_{2}\right.$ mode $)$ and $1580 \mathrm{~cm}^{-1}(\nu \mathrm{C}=\mathrm{C}$ mode $)$, respectively. The $v \mathrm{Si}-\mathrm{C}$ stretching modes of the BTA and BTE materials are observed at 530 and $545 \mathrm{~cm}^{-1}$, respectively. In this work, microRaman spectroscopy was used to study all film samples and the measurements were carried out on different regions of the film and powder samples. Regardless of the sample morphology, the samples displayed identical Raman spectra by both techniques. This implies that the framework of the periodic mesoporous organosilica film is comprised of a homogeneous distribution of $(\mathrm{OH})_{x} \mathrm{O}_{1.5-x} \mathrm{Si}-\mathrm{R}-\mathrm{SiO}_{1.5-x}(\mathrm{OH})_{x}$ building units and
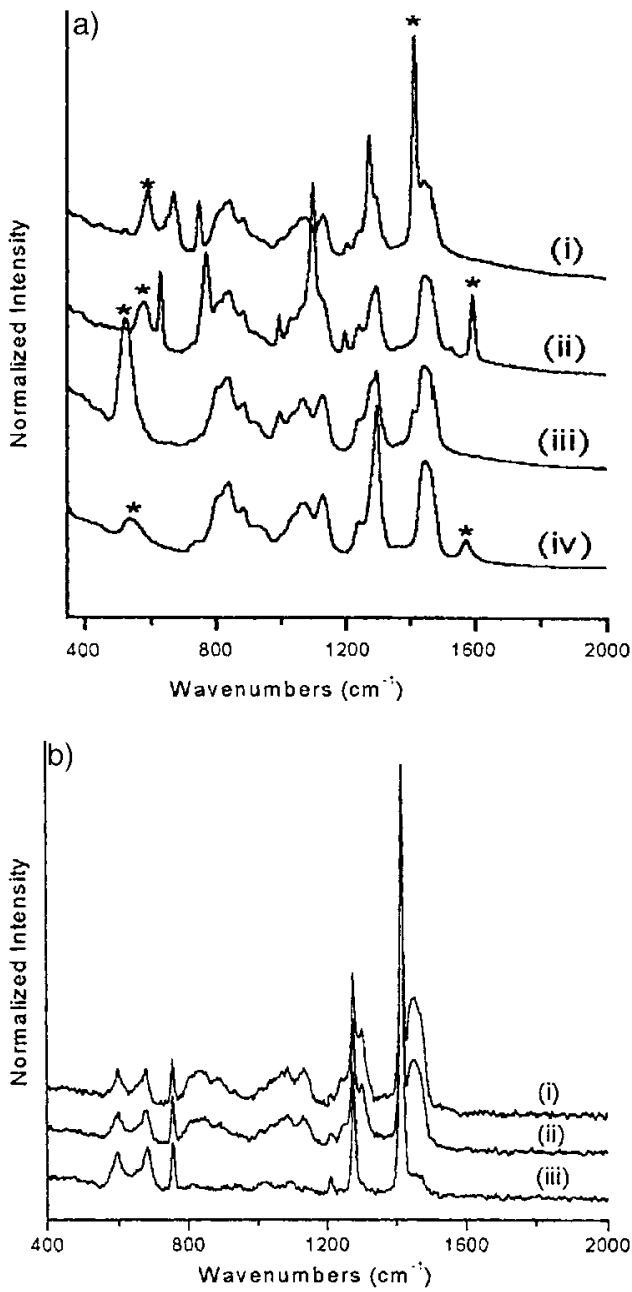

Fig. 4. a) Micro-Raman spectra of: i) BTT, ii) BTP, iii) BTA, and iv) BTE orient ed PMO film samples (* shows the $\nu \mathrm{Si}-\mathrm{C}$ and $\nu \mathrm{C}=\mathrm{C}$ bands). b) FT-Raman spectra of powdered PMO film prepared from BTT: i) as synthesized, ii) washed once with methanol, and iii) washed twice with methanol.

that the imbibed surfactant is regularly dispersed within the channels. There was no evidence for segregation or phase separation of any kind.

${ }^{1} \mathrm{H}$ magic angle spinning (MAS) NMR spectra of BTA, BTE, BTP, and BTT powdered film samples are displayed in Figure 5 a. ${ }^{1} \mathrm{H}$ NMR chemical shifts for the materials are summarized in Table 1. One of the most important features in the ${ }^{1} \mathrm{H}$ MAS NMR spectra of these PMOs is that the line widths of imbibed surfactant peaks are relatively small as a result of their high mobility in the channels. In contrast, the line widths of peaks due to bridging organic groups are much larger than those of imbibed surfactants indicating greater structural rigidity on the ${ }^{1} \mathrm{H}$ NMR time scale, which is consistent with them being an integral part of the silica framework. While peaks expected for the unsaturated organic groups were clearly distinguished, the peak assigned to the bridge-bonded ethane protons of the BTA PMO at ca. 1 ppm was not resolved. The peak at $4.5-6.5 \mathrm{ppm}$ is very sensitive to the $\mathrm{pH}$ of the synthesis mixture; it is likely to be associated with water molecules. ${ }^{[25]}$ The relatively sharp peaks at ca. $4.0 \mathrm{ppm}$ are assigned to the ethyleneoxide units of the surfactant head group. ${ }^{[25]}$ 
a)

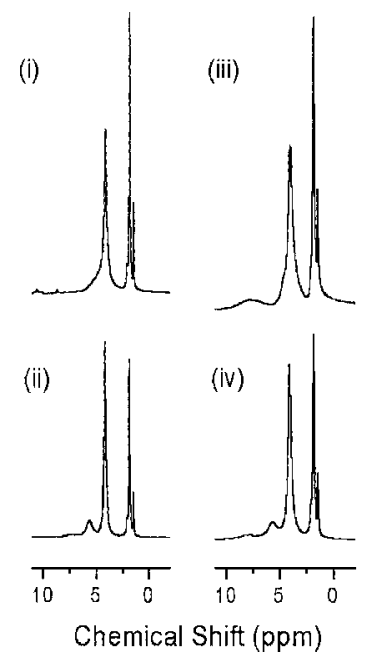

b)

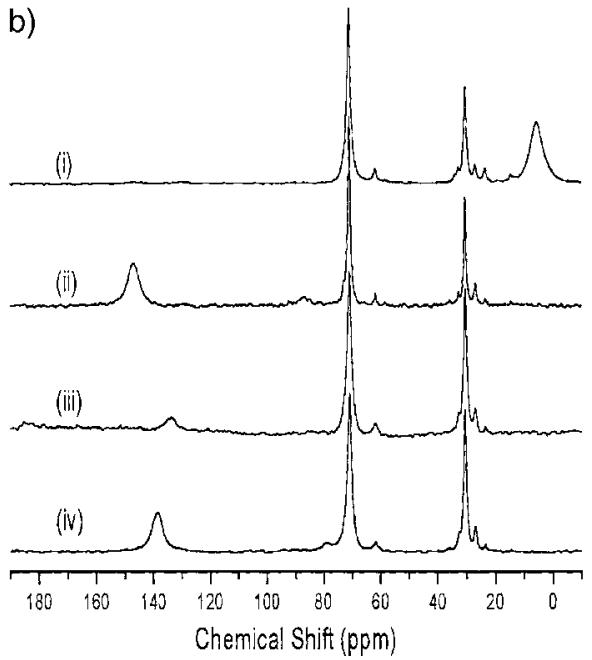

c)

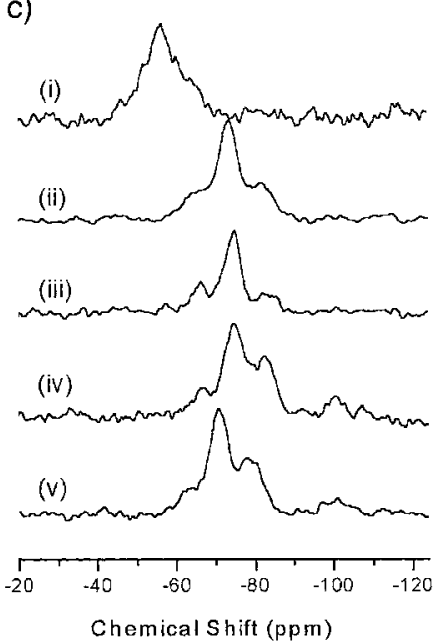

Fig. 5. a) ${ }^{1} \mathrm{H}$ MAS NMR spectra of i) BTA, ii) BTE, iii) BTP, and iv) BTT oriented PMO samples. b) Representative examples of ${ }^{13} \mathrm{C}$ CP MAS NMR spectra of i) BTA, ii) BTE, iii) BTP, and iv) BTT oriented PMO samples. c) ${ }^{29}$ Si MAS NMR spectra of i) BTA, ii) BTE, iii) BTT, iv) BTT after one day acid-water vapor post-treatment, and v) BTP oriented PMO sample after one day of acid-water vapor post-treatment.

Table 1. Assignments for ${ }^{1} \mathrm{H}$ MAS NMR spectra [ppm].

\begin{tabular}{lcccc}
\hline Assignment & BTA & BTE & BTP & BTT \\
\hline Surfactant (tail) & $1.4,1.8$ & $1.4,1.8$ & $1.4,1.8$ & $1.4,1.8$ \\
Surfactant (head) & 4.1 & 4.1 & 4.1 & 4.1 \\
Organic Framework & not resolved & 6.9 (broad) & 7.7 (broad) & 8.0 (broad) \\
\hline
\end{tabular}

Further evidence for framework integration stems from ${ }^{13} \mathrm{C}$ cross polarization (CP) MAS and ${ }^{29} \mathrm{Si}$ MAS NMR measurements. The ${ }^{13} \mathrm{C}$ CP MAS NMR spectra of the four PMO samples (Fig. 5b) provide considerable structural detail. In addition to the surfactant signals, the spectra showed peaks that were characteristic of the organic moieties as listed in Table 2. ${ }^{[25]}$ Inequivalent carbon resonances of the benzene and thiophene moieties inside the framework in the BTP and BTT PMOs were not resolved. This may be related to the rigidity and different microenvironments of the aromatic rings in the framework, leading to line broadening.

${ }^{29}$ Si MAS NMR spectra were recorded without cross-polarization to obtain a measure of the relative number of different kinds of silicon sites in the PMO film samples. As the relaxation times for the silicons are very long, NMR experiments were performed with $20^{\circ}$ pulses and a delay time of $100 \mathrm{~s}$. Within this time period, all the ${ }^{29} \mathrm{Si}$ nuclei relax and the spectrum collected allows quantification of the silicon environments. The spectra of the as-synthesized films show only resonances due to $T$ sites, with different chemical shifts, which depend upon the bridging organic groups, see Table 3. For ex-

Table 2. Assignments for ${ }^{13} \mathrm{C} \mathrm{CP}$ MAS NMR spectra $[\mathrm{ppm}]$.

\begin{tabular}{lcccc}
\hline Assignment & BTA & BTE & BTP & BTT \\
\hline Surfactant (tail) & $23,27,30,32$ & $23,27,30,32$ & $23,27,30,32$ & $23,27,30,32$ \\
Surfactant (head) & 61,71 & 61,71 & 61,71 & 61,71 \\
Organic Framework & 6 & 147 & 134 & 139 \\
\hline
\end{tabular}

Table 3. Assignments for ${ }^{29} \mathrm{Si}$ MAS NMR spectra [ppm].

\begin{tabular}{ccccc}
\hline Assignment & BTA & BTE & BTP & BTT \\
\hline $\mathrm{T}_{1}$ & -45 & -64 & -67 & -66 \\
$\mathrm{~T}_{2}$ & -54 & -70 & -75 & -74 \\
$\mathrm{~T}_{3}$ & -65 & -82 & -83 & -83 \\
\hline
\end{tabular}

ample, the ${ }^{29} \mathrm{Si}$ NMR spectrum of the BTE materials displays a 1:5:2 intensity pattern ascribed to $\mathrm{T}_{1}\left(\mathrm{C}-\mathrm{Si}(\mathrm{OSi})(\mathrm{OH})_{2}\right), \mathrm{T}_{2}$ $\left(\mathrm{C}-\mathrm{Si}(\mathrm{OSi})_{2}(\mathrm{OH})\right)$, and $\mathrm{T}_{3}\left(\mathrm{C}-\mathrm{Si}(\mathrm{OSi})_{3}\right)$ framework sites, respectively (Fig. 5c). The absence of $\mathrm{Q}$ sites observed in the ${ }^{29} \mathrm{Si}$ NMR spectra indicates there are negligible cleavage of $\mathrm{Si}-$ $\mathrm{C}$ bonds during the self-assembly and organosilicate hydrolytic polycondensation processes are negligible. Furthermore, the observed $T_{3} / T_{2}$ ratios for as-synthesized film samples clearly show that the organosilicate polymerization is not complete. ${ }^{[27-}$ ${ }^{29]}$ However, samples that have been post-treated in an aqueous, acidic atmosphere at $80^{\circ} \mathrm{C}$ exhibit a greater population of $\mathrm{T}_{3}$ sites as expected for a framework with a higher degree of polymerization.

\section{Conclusions}

We have synthesized the first examples of oriented PMO film on a glass substrate using a non-ionic oligo(ethyleneoxide) surfactant, lyotropic liquid crystalline phase as template. Data collected from NMR, Raman, PXRD, and TEM studies confirmed the presence of bridge-bonded organic groups in the walls of the well-ordered mesoporous organosilica materials. This new type of oriented film with organic groups incorporated "inside" the framework offers numerous opportunities for selectively anchoring organometallics or inorganics in a size tunable void space for catalytic, separation, and optical applications. The incorporation of redox active bridging groups inside the walls could lead to smart composites for electrically controlled sieving or controlled delivery of chemicals.

\section{Experimental}

The synthetic approach used throughout this work will be illustrated by the preparation of a mesoporous organosilica film containing a bridging BTA group. A mixture of $2.40 \mathrm{~g} \mathrm{H}_{2} \mathrm{O}, 2.30 \mathrm{~g} \mathrm{C}_{12} \mathrm{H}_{25}(\mathrm{EO})_{10} \mathrm{H}$ (Aldrich), and $0.10 \mathrm{~g} \mathrm{HNO}_{3}$ $(6.5 \%)$ was homogenized by gentle warming on a hot plate until the liquid crystalline phase dissolved. Bis(triethoxysilyl)ethane, (EtO) ${ }_{3} \mathrm{SiCH}_{2} \mathrm{CH}_{2} \mathrm{Si}(\mathrm{OEt})_{3}$, 
(2.7 $\mathrm{g}$, Gelest) was then added to the surfactant mixture and the liquid was warmed until a clear solution was obtained. Removal of the byproduct, ethanol, by applying a gentle vacuum to the mixture gave a clear, viscous solution. The liquid crystalline phase was placed onto a glass slide where it formed a film. As polycondensation continued, the sample gradually solidified into an optically transparent film. A similar procedure works well for the other precursors used in this study. Due to the enhanced reactivity of the other precursors, the rate of the condensation polymerization needed to be more carefully controlled. This was accomplished by the addition of a smaller quantity of $\mathrm{HNO}_{3}(6.5 \%)$ to the water/surfactant mixture $(0.04 \mathrm{~g}$ in the case of BTE, $1 \mathrm{mg}$ in the case of BTP, and a very small amount or no added acid in the case of BTT) before incorporating the organosilica precursor. The amount of organosilica precursor was also varied to optimize the structural order of the mesoporous organosilica materials.

POM images were recorded in transmission mode on an Olympus BH-2 microscope using convergent white light between parallel and crossed polarizers PXRD patterns were obtained on a Siemens D5000 diffractometer using a high power $\mathrm{Cu} \mathrm{K} \alpha$ source operating at $50 \mathrm{kV} / 35 \mathrm{~mA}$. Micro-Raman spectra were obtained on an Instruments S.A. Lab Ram. Solid-state NMR spectra were recorded on a Bruker DSX 400 spectrometer. The samples were spun at 6 to $10 \mathrm{kHz}$. All chemical shift values are reported with respect to tetramethylsilane (TMS) and the following experimental parameters were employed: ${ }^{1} \mathrm{H}$ MAS NMR single pulse experiment, recycle delay of $1.0 \mathrm{~s}, \pi / 2$ pulse width of $4.0 \mu \mathrm{s}, 8$ scans, spinning rate of $8 \mathrm{kHz} .{ }^{13} \mathrm{C} \mathrm{CP}$ MAS NMR proton high power decoupling experiment, recycle delay of $10 \mathrm{~s}$, contact time $2 \mathrm{~ms}, \pi / 2$ pulse width of $5.50 \mu \mathrm{s}$, spinning rate of $8 \mathrm{kHz}, 2000-5000$ scans. ${ }^{29} \mathrm{Si}\left\{{ }^{1} \mathrm{H}\right\}$ MAS NMR single pulse experiment, recycle delay time of $100 \mathrm{~s}, \pi / 9$ pulse width of $1.5 \mu \mathrm{s}$, spinning rate of $6 \mathrm{kHz}$ 1400 scans. TEM images were obtained using a Philips 430 microscope operating at an accelerating voltage of $100 \mathrm{kV}$. The samples were embedded in epoxy resin and microtomed.

Received: December 12, 2000

[1] a) H. Hata, S. Saeki, T. Kimura, Y. Sugahara, K. Kuroda, Chem. Mater 1999, 11, 1110. b) K. M. Kemner, X. Feng, J. Liu, G. E. Fryxell, L. Q. Wang, A. Y. Kim, M. Gong, S. Mattigod, J. Synchrotron Radiation 1999, 6, 633. c) R. Ryoo, J. M. Kim, C. H. Ko, Mesoporous Mol. Sieves 1998, 117, 151.

[2] a) M. Raimondo, G. Perez, N. Sinibaldi, A. DeStefanis, A. A. G. Tomlinson, Chem. Commun. 1997, 1343. b) A. M. Bond, W. J. Miao, T. D. Smith, J. Jamis, Anal. Chim. Acta 1999, 396, 203.

[3] a) J. P. G. Pater, P. A. Jacobs, J. A. Martens, J. Catal. 1999, 184, 262 b) M. S. Morey, A. Davidson, G. D. Stucky, J. Porous Mater. 1998, 5, 195.

[4] a) T. Hirai, H. Okubo, I. Komasawa, J. Phys. Chem. B 1999, 103, 4228. b) E. Chomski, Ö. Dag, A. Kuperman, N. Coombs, G. A. Ozin, Chem. Vap. Deposition 1996, 2,8

[5] a) Y. Plyuto, J. M. Berquier, C. Jacquiod, C. Ricolleau, Chem. Commun. 1999, 1653. b) R. Ryoo, C. H. Ko, R. F. Howe, Chem. Mater. 1997, 9, 1607. c) C. H. Ko, R. Ryoo, Chem. Commun. 1996, 2467.

[6] M. J. MacLachlan, P. Aroca, N. Coombs, I. Manners, G. A. Ozin, Adv. Mater. 1998, 10, 144.

[7] a) C. T. Kresge, M. E. Leonowicz, W. J. Roth, J. C. Vartuli, J. S. Beck, Nature 1992, 359, 710. b) J. S. Beck, J. C. Vartuli, W. J. Roth, M. E. Leonowicz, C. T. Kresge, K. D. Schmitt, C. T.-W. Chu, D. H. Olson, E. W. Sheppard, S. B. McCullen, J. B. Higgins, J. L. Schlenker, J. Am. Chem. Soc. 1992, 114, 10834.

[8] a) G. A. Ozin, E. Chomski, D. Khushalani, M. J. MacLachlan, Curr. Opin. Colloid Interface Sci. 1998, 3, 181. b) K. Moller, T. Bein, Chem. Mater. 1998, 10,2950.

[9] F. Marlow, M. D. McGehee, D. Y. Zhao, B. F. Chmelka, G. D. Stucky, $A d v$. Mater. 1999, 11, 632.

[10] D. M. Antonelli, J. Y. Ying, Angew. Chem. Int. Ed. Engl. 1996, 35, 426.
[11] Z.-R. Tian, W. Tong, J. Y. Wang, N. G. Duan, V. V. Krishnan, S. L. Suib, Science 1997, 276, 926

[12] G. S. Attard, C. G. Göltner, J. M. Corker, S. Henke, R. H. Templer, Angew Chem. Int. Ed. Engl. 1997, 36, 1315.

[13] P. V. Braun, P. Osenar, S. I. Stupp, Nature 1996, 380, 325.

[14] a) M. J. MacLachlan, N. Coombs, G. A. Ozin, Nature 1999, 397, 681. b) K. K. Rangan, S. J. L. Billinge, V. Petkov, J. Heising, M. G. Kanatzidis, Chem. Mater. 1999, 11, 2629. c) M. J. MacLachlan, N. Coombs, R. L. Bedard, S. White, L. K. Thompson, G. A. Ozin, J. Am. Chem. Soc. 1999, 121 , 12005 .

[15] T. Asefa, M. J. MacLachlan, N. Coombs, G. A. Ozin, Nature 1999, 402, 867.

[16] S. Inagaki, S. Guan, Y. Fukushima, T. Ohsuna, O. Terasaki, J. Am. Chem. Soc. 1999, 121, 9611

[17] C. Yoshina-Ishii, T. Asefa, N. Coombs, M. J. MacLachlan, G. A. Ozin, Chem. Commun. 1999, 2539.

[18] T. Asefa, M. J. MacLachlan, H. Grondey, N. Coombs, G. A. Ozin, Angew. Chem. Int. Ed. 2000, 39, 1808.

[19] B. J. Melde, B. T. Holland, C. F. Blanford, A. Stein, Chem. Mater. 1999, 11 3302.

[20] T. Asefa, N. Coombs, Ö. Dag, H. Grondey, M. J. MacLachlan, G. A. Ozin C. Yoshina-Ishii, Mater. Res. Soc. Symp. Proc. 2000, 628, CC3.9.

[21] a) G. Cerveau, R. J. P. Corriu, Coord. Chem. Rev. 1998, 180, 1051 b) R. J. P. Corriu, J. J. E. Moreau, P. Thepot, M. W. C. Man, Chem. Mater 1992, 4, 1217. c) J. H. Small, K. J. Shea, D. A. Loy, J. Non-Cryst. Solids 1993, 160, 234. d) J. Wen, G. L. Wilkes, Chem. Mater. 1996, 8, 1667 e) R. J. P. Corriu, Polyhedron 1998, 17, 925. f) D. A. Loy, K. J. Shea, Chem. Rev. 1995, 95, 1431. g) C. Sanchez, F. Ribot, New J. Chem. 1994, 18, 1007. h) U. Schubert, N. Hüsing, A. Lorenz, Chem. Mater. 1995, 7, 2010

[22] For examples of MCM-41 materials with terminal organic groups included in the synthesis, see: a) M. H. Lim, A. Stein, Chem. Mater. 1999, 11, 3285. b) M. H. Lim, C. F. Blanford, A. Stein, J. Am. Chem. Soc. 1997, 119, 4090 c) M. H. Lim, C. F. Blanford, A. Stein, Chem. Mater 1998, 10, 467. d) S. L. Burkett, S. D. Sims, S. Mann, Chem. Commun. 1996, 1367. e) K. Moller, T. Bein, R. X. Fischer, Chem. Mater. 1999, 11, 665. f) S. D. Sims, S. L. Burkett, S. Mann, Mater. Res. Soc. Symp. Proc. 1996, 431, 77. g) D. J. Macquarrie, Chem. Commun. 1996, 1961. h) C. E. Fowler, S. L. Burkett, S. Mann, Chem. Commun. 1997, 1769. i) F. Babonneau, L. Leite, S. Fontlupt, J. Mater Chem. 1999, 9, 175. j) W. M. Van Rhijn, D. E. De Vos, B. F. Sels, W. D. Bossaert, P. A. Jacobs, Chem. Commun. 1998, 317. k) W. Van Rhijn, D. De Vos, W. Bossaert, J. Bullen, B. Wouters, P. Grobet, P. Jacobs, Stud. Surf. Sci. Catal. 1998, 117, 183 .

[23] For examples of MCM-41 materials with organosiloxane groups grafted post-synthesis, see: a) D. Brunel, A. Cauvel, F. Fajula, F. DiRenzo, Stud. Surf. Sci. Catal. 1995, 97, 173. b) J. F. Díaz, K. J. Balkus, F. Bedioui, V. Kurshev, L. Kevan, Chem. Mater. 1997, 9, 61. c) L. Mercier, T. J. Pinnavaia, Adv. Mater. 1997, 9, 500. d) J. S. Beck, J. C. Vartuli, W. J. Roth, M. E. Leonowicz, C. T. Kresge, K. D. Schmitt, C. T.-W. Chu, D. H. Olson, E. W Sheppard, S. B. McCullen, J. B. Higgins, J. L. Schlenker, J. Am. Chem. Soc. 1992, 114, 10834 . e) P. Sutra, D. Brunel, Chem. Commun. 1996, 2485. f) K Moller, T. Bein, Chem. Mater. 1998, 10, 2950. g) X. Feng, G. E. Fryxell, L. Q. Wang, A. Y. Kim, J. Liu, K. M. Kemner, Science 1997, 276, 923. h) D. S. Shephard, W. Zhou, T. Maschmeyer, J. M. Matters, C. L. Roper, S. Parsons, B. F. G. Johnson, M. J. Duer, Angew. Chem. Int. Ed. 1998, 37 , 2719.

[24] G. S. Attard, J. C. Glyde, C. G. Göltner, Nature 1995, 378, 366.

[25] Ö. Dag, A. Verma, G. A. Ozin, C. T. Kresge, J. Mater. Chem. 1999, 9, 1475.

[26] D. Zhao, P. Yang, N. Melosh, J. Feng, B. F. Chmelka, G. D. Stucky, Adv. Mater. 1998, 10, 1380.

[27] B. Boury, R. J. P. Corriu, V. L. Strat, P. Delord, New J. Chem. 1999, 23, 531

[28] R. J. P. Corriu, D. Leclercq, Angew. Chem. Int. Ed. Engl. 1996, 35, 1420.

[29] R. J. P. Corriu, J. J. E. Moreau, P. Thepot, M. W. C. Man, Chem. Mater. 1992, 4,1217 